\title{
JOSÉ MARÍA RIVAS GROOT: UN ACERCAMIENTO A LA DIMENSIÓN PRAGMÁTICA DE SU NARRATIVA BREVE EN «ROCINANTE» Y «DÍA DE INOCENTES»
}

doi.org/10.15452/SR.2021.21.0006

ORCID ID: 0000-0002-2302-6735

\author{
Pedro Javier Casas Malagón \\ Universidad de La Sabana \\ Colombia \\ pedrocasma@unisabana.edu.co
}

Resumen. Dueño de un intelecto multiforme, José María Rivas Groot (Bogotá, 1863-Roma, 1923) se destacó como hombre público y de letras. Director interino de la Biblioteca Nacional, senador, ministro de estado, ministro plenipotenciario de Colombia ante la Santa Sede, periodista, editor y escritor, vocación esta última forjada en el seno familiar y en la que se manifiesta su pensamiento conservador y cristiano, defensor de la tradición. Su producción intelectual cubre una amplia variedad de géneros literarios: poesía, novela, cuento, teatro y ensayo histórico, entre otros. Si bien su narrativa breve ha permanecido, en cierto modo, al margen de antologías y estudios, es testimonio fiel de su estilo y pensamiento en una época convulsa, afectada por fuertes transformaciones sociales y políticas, enmarcada por el tránsito del siglo XIX al XX. A través de dos de sus cuentos catalogados como inéditos ${ }^{1}-$ «Rocinante» $\mathrm{y}$ «Día de inocentes»-, este artículo ofrece un acercamiento a su narrativa breve desde una perspectiva pragmática con el propósito de revelar su sentido y valor intencional, en el que la transtextualidad, el simbolismo y la ironía son recursos a los que acude, como fiel representante de la ciudad letrada, para expresar su postura ante circunstancias, comportamientos y actitudes propias de su espacio-tiempo, que continúan vigentes hasta hoy.

Palabras clave. José María Rivas Groot. Narrativa breve. Pragmática. Transtextualidad. Simbolismo. Ironía.

1 «Rocinante» $\mathrm{y}$ «Día de inocentes» forman parte de los nueve cuentos no publicados de José María Rivas Groot cedidos por su familia a George N. Castellanos para el libro Modernismo y modernidad en José María Rivas Groot, editado por el Instituto Caro y Cuervo (1998).

(i) () () This work is licenced under the Creative Commons Attribution 4.0 International license for non-commercial purposes. 


\begin{abstract}
José María Rivas Groot: an Approach to the Pragmatic Dimension of his Short Stories in «Rocinante» and «Día de inocentes». Having a multiform intellect, José María Rivas Groot (Bogotá, 1863-Rome, 1923) stood out as a public figure and a man of letters. Acting director of the National Library, senator, minister of state, plenipotentiary minister of Colombia to the Holy See, journalist, editor and writer, vocation this latter forged in the family bosom and in which his conservative and Christian thought, defender of tradition, is manifested. His intellectual production covers a wide variety of literary genres: poetry, novel, short stories, theater and historical essays, among others. Although his short stories have remained, in a way, on the sidelines of anthologies and studies, it is a faithful testimony of his style and thought, in a time of turmoil, affected by strong social and political transformations, framed by the transition from the $19^{\text {th }}$ to the $20^{\text {th }}$ century. Through two of his short stories classified as unpublished, Rocinante and Dia de inocentes, this article offers an approach to his short stories from a pragmatic perspective with the purpose of revealing its meaning and intentional value, in which transtextuality, symbolism and irony are resources to which he turns, as a faithful representative of the lettered city, to express his position in the face of circumstances, behaviors and attitudes typical of his space-time, which remain in force until today.
\end{abstract}

Keywords. José María Rivas Groot. Short stories. Pragmatic. Transtextuality. Symbolism. Irony. 


\section{Introducción}

José María Rivas Groot (Bogotá, 18 de abril de 1863-Roma, 26 de octubre de 1923) es un referente de su tiempo. Su sólida formación le permitió incursionar en ámbitos como la política, la diplomacia y la cultura. Fue escritor, periodista y editor; tuvo a su cargo la dirección de la Biblioteca Nacional (1888) y presidió la Academia Colombiana de Historia (1907-1908). Sus inclinaciones políticas y literarias, como señala Gómez Restrepo en su nota póstuma, son un legado familiar:

Era su padre don Medardo Rivas, miembro de esa falange de jóvenes liberales que [...] se hicieron heraldos de atrevidas y radicales innovaciones, que proclamaban en estilo brillante, de corte francés, como era francés su pensamiento político...

Por su madre era [...] nieto del venerable tradicionalista don José Manuel Groot, católico y conservador a macha martillo, [...] saleroso autor de artículos de costumbres.

En el nieto prevalecieron, en materia religiosa y política, las influencias tradicionales. Aun cuando veneraba a su padre y admiraba los aspectos brillantes de su talento literario, se sintió más cercano a su abuelo en materia de ideas, y siguió sus huellas como apologista y como escritor político... (Gómez Restrepo, s.f.: 1).

Su obra abarca la poesía, la novela, el cuento, el teatro, la crítica literaria, los estudios históricos y económicos... Si bien es reconocido principalmente por su poesía, en particular el poema «Constelaciones» (1892), considerado «una de las notas líricas más altas del Parnaso colombiano» (Maya, 1951: 7), sus dos novelas cortas: Resurrección (1902) y El triunfo de la vida (1915) han merecido igual admiración. Precisamente, El triunfo de la vida recibió el premio Conde de Villafuertes el mismo año de su publicación (cf. Castellanos, 1998: 71).

Dentro de su novelística, Pax (1907), escrita en colaboración con Lorenzo Marroquín, ocupa un lugar especial. Aun cuando fue publicada de manera apresurada y sin su consentimiento, tuvo una gran aceptación, debido, entre otros, a la polémica que originó. La novela, escrita en clave, critica la debacle causada por la guerra de los Mil Días², y retrata en sus páginas a figuras reconocidas de la vida social y política de aquel entonces (cf. Santa, 1990: 444).

Por otra parte, su narrativa breve, aun cuando no ha despertado el mismo interés y ha permanecido, de cierto modo, al margen de antologías y estudios, «relieva vigorosamente, las mejores cualidades de [su] estilo y de [su] pensamiento...» (Maya, 1951: 20). Está conformada por veintiuna obras, doce de las cuales fueron publicadas, en su mayoría, entre 1915 y 1917, en diferentes diarios de Colombia y principalmente de España. Estas son: «Julieta», «Bodas de oro», «Palabra de rey», «El vaso de agua», «Víctimas de la guerra», «El águila de acero», «El

2 La guerra de los Mil Días (17 de octubre de 1899-21 de noviembre de 1902), uno de los conflictos más devastadores de la historia de Colombia, enfrentó a los dos partidos políticos tradicionales: liberal y conservador, divididos, a su vez, en facciones, unas más radicales que otras. Luego de un periodo de hegemonía conservadora, iniciado en 1886, acompañado de mecanismos restrictivos contra el liberalismo, el ala belicista liberal encontró en las armas la única forma para retomar el poder, si bien, a la postre fue derrotado. Las consecuencias: miles de muertos, un país destruido, la economía en ruinas, y la consiguiente separación del estado de Panamá en 1903 (cf. Ortiz, 2010: 247-250). 
conquistador de Roma», «Un discípulo de Nietzsche» y «La novela en la historia» (cf. Castellanos, 1998: 67). Las nueve obras restantes son consideradas inéditas. ${ }^{3}$

La difusión posterior de su cuentística ha sido, en realidad, escasa. En 1936, el Ministerio de Educación Nacional, como parte de la colección Biblioteca Aldeana de Colombia, publicó el libro Cuentos por José María y Evaristo Rivas Groot, el cual incluyó su novela corta Resurrección y el cuento «Julieta», así como algunas obras de su hermano Evaristo Rivas Groot. Posteriormente, en 1951, el Ministerio de Educación Nacional, como parte de la colección Biblioteca Popular de Cultura Colombiana, publicó el libro José María Rivas Groot. Novelas y cuentos, compuesto por sus dos novelas cortas y los doce cuentos antes referidos.

Ahora bien, el estudio de su narrativa se ha centrado principalmente en Resurrección y El triunfo de la vida, sus dos novelas cortas. En el caso de los cuentos, su análisis se ha circunscrito a dos libros publicados por el Instituto Caro y Cuervo: Modernismo y modernidad en José María Rivas Groot, de George N. Castellanos (1998), y Narrativa de José María Rivas Groot: algunas aproximaciones filológico-estilísticas, de Homero Mercado Cardona (1999).

Castellanos, en su libro, destina uno de los capítulos a la revisión concreta de la cuentística de Rivas Groot. En él no solo considera las doce obras que forman parte de José María Rivas Groot. Novelas y cuentos, sino que incorpora nueve cuentos inéditos: «Corazón en alcohol», «Día de inocentes», «El himno del soldado», «El secreto del brujo», «El trasatlántico», «En la boca del león», «Los dos soberanos», «Rocinante» y «Un cuento original». El estudio de Castellanos (1998: 154), en sus propias palabras: «representa el primer enfoque totalizador de los cuentos de Rivas Groot», que agrupa las obras en cuatro rubros: modernidad socio-política, crítica de la modernidad del progreso, modernidad y cristianismo, y modernidad estética.

«Rocinante» $\mathrm{y}$ «Día de inocentes», los cuentos elegidos para este acercamiento, se enmarcan en la categoría definida por Castellanos como modernidad estética, entendiéndose esta como:

... todas las nuevas ideas que sustentan el asunto de sus cuentos [Rivas Groot] acerca de la creación artística, el decadentismo, la modernidad literaria, la originalidad, el plagio, la misión visionaria del artista en la sociedad, toda una ideología que revela una reflexión sobre el arte modernista... (Castellanos, 1998: 175).

Para finalizar, vale anotar que las citas textuales de los cuentos hacen referencia a su publicación en el libro ya mencionado de Castellanos (1998): Modernismo y modernidad en José María Rivas Groot.

\section{2. «Rocinante»: transtextualidad y simbolismo}

En un relato breve, el título es por excelencia su antesala, y su propósito, en palabras de Alarcos Llorach (1989: 171), es estimular «el interés del lector». En este caso, «Rocinante» alude a la obra cumbre de Miguel de Cervantes Saavedra, Don Quijote de la Mancha. Y, con ello, Rivas Groot deja entrever el carácter transtextual que enmarca la historia, y que de forma directa remite a su protagonista: un rocín.

3 Véase la nota al pie 1. 
Fue luego a ver su rocín, y aunque tenía más cuartos que un real y más tachas que el caballo de Gonela, que «tantum pellis et ossa fuit», le pareció que ni el Bucéfalo de Alejandro ni Babieca el del Cid con él se igualaban. [...] y así, después de muchos nombres, que formó, borró y quitó, añadió, deshizo y torno a hacer en su memoria e imaginación, al fin le vino a llamar «Rocinante», nombre, a su parecer, alto, sonoro y significativo... (Cervantes; Rico; Vargas Llosa, 2004: 31-32).

Este fragmento de $E l$ Quijote expresa la esencia del Rocinante anhelado por un célebre pintor, al que luego de resultarle esquivo el hallazgo del modelo perfecto, «digno, colaborador generoso y voluntario de aquel Ingenioso Hidalgo...» (Castellanos, 1998: 274), deja tan solo en bosquejos aquella obra. Sin embargo, una tarde, pasado un año, al dar por terminada una de las sesiones de trabajo del retrato de un famoso general, «ante sus ojos, de carne y huesos, real e ideal» (Castellanos, 1998: 274) emerge su Rocinante, entre un grupo de caballos secos y desgarbados, camino de la plaza de toros. El pintor no podía permitirse perderlo y envió de inmediato por él. Ahora podía, por fin, retomar su proyecto. El general, quien se había interesado por el cuadro inconcluso, al conocer por boca del pintor que aquel caballo, finalmente hallado, tenía una notoria cicatriz en el cuello, recordó de inmediato al corcel que otrora lo acompañó en las batallas.

Habían pasado muchos años y, naturalmente, la estampa de Rocinante distaba de aquella que el general guardaba en su memoria. No obstante, había algo que distinguía a aquel caballo de sus recuerdos: reaccionaba con entusiasmo a las viejas marchas de guerra. Así, con el beneplácito del pintor y por «orden del capitán general, una de las bandas militares se instaló al día siguiente en el parque del artista» (Castellanos, 1998: 279) a fin de ver la reacción del caballo. Ante el redoble de tambores y el restallar de cobres y clarines, Rocinante respondió con el mismo brío y exaltación de otros tiempos. Finalmente, la pintura de El Quijote recibió la medalla de oro en la exposición de ese año, pero Rocinante, su modelo, no pudo con la gloria evocada y la emoción de aquella tarde. «A la mañana siguiente halló el mozo de servicio intacta la ración de azúcar y de avena, y vio en el lecho de tamo, rígido, el cadáver de Rocinante» (Castellanos, 1998: 280).

Rivas Groot es testigo y parte «de las manifestaciones culturales de un medio y una época que estaban significados por el europeísmo, fuera de lo cual no existía posibilidad de creación, so pena de incurrir en delito de leso crimen estético» (Mercado, 1999: 69), y «Rocinante» es reflejo de ello. La historia se sitúa en la ciudad de Madrid: «Tenía el pintor su estudio a la entrada de esta Villa y Corte, en el extremo de la calle de Alcalá, no lejos de la plaza de toros» (Castellanos, 1998: 274). Aunque no hay una referencia explícita a la época, hay elementos que permiten enmarcarla. La exposición en que participa el pintor parece corresponder con la Exposición Nacional de Bellas Artes celebrada en Madrid a partir de 1856, en cuyos certámenes, a lo largo de la segunda mitad del siglo XIX, tuvo una importante presencia el tema cervantino (cf. Gutiérrez Burón, 2008: 456). Por otra parte, hay un indicio temporal adicional, el general, en una de sus conversaciones con el pintor, rememora sus ya lejanas incursiones en Marruecos: «Es singular... No digo que sea el mismo... no podría ser... pero a mí, en Marruecos, me hirieron así un caballo, un magnífico caballo de pura sangre» (Castellanos, 1998: 277). Justamente, ente 1859 y 1860 tuvo lugar la guerra de África, que enfrentó a España con el sultanato de Marruecos, y en la cual la ocupación del puerto de Tánger fue fundamental para la victoria de España. La 
marcha triunfal interpretada por la banda militar para Rocinante es, precisamente, La victoria de Tánger.

«Rocinante» es un relato en que el autor adopta un tono solemne y nostálgico con el cual acentúa la emotividad propia de la evocación de tiempos idos. Recuerdos que surgen no solo en la voz de los personajes, sino en la de un narrador omnisciente y heterodiegético, que penetra incluso en el sentir de Rocinante, más allá de su aparente naturaleza irracional. Es así como a través de preguntas que no buscan, en realidad, una respuesta, el narrador involucra al lector en un diálogo simulado que enfatiza ese sentir:

¿Comprendió el rocín la nueva situación que le deparaba la suerte? ¿Adivinó el noble fin a que se le destinaba? ¿Presintió que su esbelta figura, al lado de la inmortal efigie de Don Quijote, había de pasar en el lienzo, por magia del pintor, a los siglos venideros? (Castellanos, 1998: 276).

Así, el cuento se construye a partir de una modalidad textual heterogénea y polisecuencial con predominio de lo narrativo y dialógico, a la que se suman tintes argumentales conferidos por las erotemas. Se soporta, además, en una estructura bipartita de dos actos, en cuyos epígrafes se hace presente, al igual que en el título, su función referencial, solo que en este caso denotan su trama individual: I. Su hallazgo y II. Su muerte. Y, a la vez, trazan uno de los tópicos literarios que marca la historia: memento mori, el carácter cierto de la muerte:

Tal vez con misterioso instinto presienten los jamelgos su próximo fin, y con resignación silenciosa, gachas las orejas, la pupila turbia por un vaho azulino, el labio caído, la lengua oscilante entre los dientes, cabecean con tristeza, tropiezan con laxitud, doblegan el cuello hacia el polvo de la carretera como buscando el último reposo... (Castellanos, 1998: 275).

Por otra parte, la noción de verdad en la comunicación literaria es sustituida por el concepto de verosimilitud, y la referencia a la realidad es suplida por el de ficcionalidad, rasgo pragmático del discurso literario. Como parte de esa ficcionalidad, es habitual la aparición de voces simultáneas en el texto literario. Esta polifonía se muestra en dos dimensiones: la transtextualidad y la polifonía de emisor y receptor (cf. Gutiérrez Ordóñez, 2020: 47).

La naturaleza transtextual de «Rocinante» no reside solo en la relación de intertextualidad con El Quijote. Aun cuando desde el título mismo hay una alusión a la obra de Cervantes, su presencia se manifiesta como hipertexto, a través de su transformación en el texto mismo:

—¿Esto qué es? - preguntó al artista-.

-Un proyecto de cuadro sobre Don Quijote... Hace un año que está inconcluso, por falta de un modelo para Rocinante (Castellanos, 1998: 273).

Este cambio de representación artística a una forma pictórica dentro del relato, se constituye en una transposición de tipo hiperestética, que, a su vez, se convierte en hipotexto para una transformación temática. Si bien los signos de identidad de Rocinante, en líneas generales, se conservan, la imagen renovada que de él desea plasmar el pintor afecta el universo diegético, dando lugar a una transposición heterodiegética (cf. Genette, 1989: 379): 
Dolíase el artista de ver, en no pocas estampas, menguada la figura de Rocinante, sin voluntad, sin bríos, sin coraje, más flaco de ánimo que de carnes... iAh! No así lo concebía, antes bien, se lo representaba digno de servir y de acompañar al buen caballero, en la paz y en la lucha, ya en el noble ejercicio de la caza, emulando a aquel «galgo corredor» que figura en la primera página, como en las aventuras y peligros donde se mostró sin tacha y sin miedo... (Castellanos, 1998: 274).

Asimismo, la pintura, en el relato, no es solo el objeto de realización y representación de la hipertextualidad como forma de transtextualidad, es la depositaria de glorias pasadas, cuyo carácter efímero busca ser revertido; la naturaleza fugaz de los laureles en la vida: sic transit gloria mundi, que recae tanto en la figura del general como de Rocinante. La pintura es, por tanto, una alegoría del heroísmo:

A él debo [Rocinante]... suponiendo que sea el mismo, tres cruces de esas que Ud. ha pintado de un modo tan flamante... iAh! Era de verlo, pasado ya el combate, cómo sentía el orgullo de la victoria, la dicha del triunfo, de las aclamaciones... (Castellanos, 1998: 278).

Ahora bien, aun cuando «Rocinante» exhibe una temática en torno a la creación artística no solo como reproducción de un modelo, sino como representación de su actitud, vinculada a la valentía y a la gloria de la guerra, y su consecuente búsqueda de la posteridad; subyace en este cuento una simbología con trasfondo sociopolítico, que puede ser considerada como una manifestación del yo real (autor) hacia el tú real (lector), por medio del yo y tú fictivos: la polifonía de emisor y de receptor antes mencionadas (cf. Gutiérrez Ordóñez, 2020: 46).

La referencia expresa a las luchas en Marruecos, las actitudes proyectadas en la conducta de Rocinante, el fragor de la batalla evocado por la marcha triunfal, así como los tópicos literarios que subyacen en el relato mismo son, entre otros, algunos de los elementos que soportan la postura crítica de Rivas Groot a la guerra, que no es ajena, es visible, por cierto, en otras de sus obras como Pax y «Víctimas de la guerra». En la primera de ellas, novela en clave escrita a cuatro manos con Lorenzo Marroquín, publicada en Bogotá, en 1907, denuncia la devastación de la guerra de los Mil Días (1899-1902). La segunda, cuento publicado en Zamora, España, en 1917, hace patente la ruina de los pueblos, la destrucción de los recursos y la pérdida de vidas inocentes, ajenas al conflicto (cf. Castellanos, 1998: 165).

Así pues, el orgullo del general al relatar el proceder de su caballo en el campo de batalla expresa la ironía inmersa en el absurdo de la guerra:

... Con los primeros disparos, con los primeros toques de clarín, antes de sentir la espuela, mordía el freno, abría la nariz como aspirando el humo de la pólvora, y, lleno de entusiasmo, sin darme tiempo más que para afianzarme en los estribos, se lanzaba a fondo, al centro del combate, como resuelto a romper con el pecho las filas del enemigo (Castellanos, 1998: 278).

De igual modo, la dualidad del furor caótico de la guerra y el falaz encanto de la gloria que se conjugan, nublando la razón y engendrando destrucción:

... en la explosión de los cobres oye el estruendo de los arcabuces; oye en los clarines las dianas de los ataques, la vocería del enemigo, [...] se revuelve con magníficos arranques, sacudido por la rabia 
del combate, por el noble estremecimiento de la gloria. Y ciego, feliz, triunfador, rompiendo las macetas de hortensias, saltando sobre los tiestos de geranios, nervioso al herirse con las espinas de los rosales, y creyendo ver la sangre en los claveles, rompe y rasga y acrecienta los estruendos de la música con los destrozos, y en la pupila deja ver una llama de locura, último reflejo de las antiguas glorias (Castellanos, 1998: 279-280).

Cabe preguntarse si «Rocinante» fue motivado por un hecho en particular, como fue el caso de Pax. Aun cuando se desconoce la fecha en que este cuento vio la luz, la razón para escribirlo podría estar relacionada con la estadía de Rivas Groot en Madrid entre 1915 y 1920, y el momento sociopolítico que España vivía por ese entonces: la guerra del Rif (1911-1927), conflicto que, como afirma Iglesias Amorín (2014: 60): «... removió la sociedad española desde sus cimientos, pues su coste humano y económico fue elevadísimo». De cualquier modo, esto es solo una hipótesis.

\section{3. «Día de inocentes»: una sátira a la ciudad letrada}

El 28 de diciembre es la fecha en que la Iglesia Católica recuerda a sus primeros mártires: los santos inocentes. Inocencia que alude al estado de indefensión de los niños sacrificados, sometidos al poder de un rey, y ajenos a las razones de su crueldad. Inocencia que es, también, la vulnerabilidad que la ingenuidad misma supone frente al poder de la astucia y el engaño. Así pues, la inocencia y su carácter polisémico se conjugan en el título de este cuento, que apunta a la conmemoración de un remoto episodio hagiográfico, pero cuyo sentido ya no es el mismo y es, por tanto, una insinuación.

Precisamente, un 28 de diciembre, don Narciso Gómez Fernández, un «hombre práctico, de pocas letras, de buen sentido y mejores rentas» (Castellanos, 1998: 206), inició el día con desconfianza y la firme decisión de no permitirse caer en el juego de la burla. Sin embargo, como una broma de la vida misma, un aviso clasificado terminó por convertirlo en el autor de una voluminosa obra histórico-arqueológica. Este equívoco, que empezó con la publicación de este anuncio, pasó a ser pronto el runrún de los copistas en la calle, y en cuestión de algunos días a tornarse en noticia y en disputa de los diarios. Don Narciso, quien en principio no comprendía lo que ocurría, empezó a aceptar con naturalidad las adulaciones y optó por seguir el juego que las circunstancias le proponían. Era, ahora, un ilustre autor y su supuesta obra, calificada como monumental. ${ }^{4}$ No tardaron, a la sazón, en llegar los ofrecimientos deslumbrantes de los editores y en abrirse las puertas de los salones del gran mundo y de la Academia. Con el pasar de los meses y los años, «los escribientes renunciaron al honor de obtener la copia, los gacetilleros y los editores a la dicha de obtener la lectura o de comprar el manuscrito» (Castellanos, 1998: 212). A la muerte del maestro, ${ }^{4}$ «una comisión de la Academia fue a su aposento, para clasificar y recoger los papeles, para salvar el manuscrito de la "obra”...» (Castellanos, 1998: 212), pero no hallaron nada. Las suposiciones, entonces, empezaron a circular al interior de la Academia: «el autor sostenía correspondencia con numerosos sabios de Europa... Acaso alguno de ellos hubiese recibido el precioso deposito... Tal vez una academia extranjera, más afortunada, [lo]

4 El uso de la letra itálica o cursiva obedece al carácter irónico de tales calificaciones. 
conserva en sus archivos...» (Castellanos, 1998: 212). Por tanto, se designó una comisión de dos académicos para trasladarse al extranjero y viajar a Alemania y Holanda, a fin de rescatar el manuscrito de aquella obra desconocida.

El tejido de circunstancias y sucesos que rodean el discurrir del protagonista por el mundo de las letras y la historia se articulan en una combinación de secuencias dialógicas, narrativas y descriptivas, enmarcadas por la sátira, que, en últimas, se constituye en el sustrato pragmático del discurso literario. La intención comunicativa que allí subyace se corresponde con la postura crítica de Rivas Groot a diferentes ámbitos de la sociedad. De este modo, la ironía, el silencio, la kinésica del protagonista, acompañados de algunos elementos autobiográficos, son recursos a los que el autor acude para expresar su intencionalidad.

Justamente, la ironía, como hecho pragmático de índole contextual, sujeto a las intenciones y capacidades interpretativas (cf. Reyes, 1984: 154), marca la línea argumental del relato: la mitificación de una obra ilusoria y de su ilustre autor, un hombre de pocas letras, que termina por ser considerado un maestro, y, tras su muerte, elevado a la categoría de sabio. ${ }^{4}$ Si bien la configuración de este mito inicia con un hecho fortuito e inopinado, es la actitud misma del protagonista, con el concurso no expreso de algunos círculos, la que lo determina y consolida. $\mathrm{Y}$ es allí donde el silencio tiene lugar; el silencio, un tipo de acto de habla no verbal con estatus ilocucionario, cuya acción pragmática reside en la decisión de decir algo callando (cf. Vallejo, 2011; Camargo y Méndez, 2014; Méndez, 2014; citados por Méndez Guerrero, 2016: 175). Este mutismo es, en principio, un efugio a la embestida de preguntas por parte de los copistas, y así lo deja ver el narrador, omnisciente y heterodiegético, con un tono de sorna en su voz: «por fortuna había logrado evitar las preguntas demasiado comprometedoras... había conservado ese silencio discreto, digno, de autor que se respeta» (Castellanos, 1998: 210).

El silencio, posteriormente, adopta un carácter discursivo e intensificador, acentuado por los gestos y la corporalidad: «El señor Gómez sonreía, se inclinaba modestamente, enarcaba las cejas... y no accedía. [...] echaba atrás la cabeza, fruncía los labios, miraba con desdén al periodista... y permanecía inmutable...» (Castellanos, 1998: 211). En sus actitudes se hace patente, además, una pretensión velada: «... se erguía en su pedestal, digno, silencioso, impenetrable; ni requería ni rechazaba la gloria; era un hombre superior a todos los estímulos de la fama, a todas las tolerables vanidades del mundo... Y esto mismo acrecentaba su gloria...» (Castellanos, 1998: 211), actitudes que remiten a su nombre: Narciso, con la correspondiente alusión al mito de Ovidio.

Ahora bien, a lo largo de este cuento, los diferentes ámbitos de la sociedad allí reflejados no escapan a los apuntes críticos de Rivas Groot, lo que no es arbitrario, de hecho, obedece a la facultad misma que su propia experiencia como periodista, editor, historiador y diplomático, entre otros, le confiere; es decir, como miembro insigne de esa ciudad letrada planteada por Ángel Rama (1984). Así pues, cuestiona el papel del periodista y de la prensa escrita, contrapone el valor de la veracidad frente al sensacionalismo y defiende el legítimo quehacer periodístico:

En la sección de «Indicaciones Mundanas» el hábil gacetillero Pik-Pak se apresuró a dar cuenta de la obra, no sin asegurar que por ser un gacetillero para quien no existían ni puerta cerrada, ni 
secreto diplomático, ni manuscrito ignoto, había obtenido la promesa de una próxima lectura de aquella obra que «a no dudarlo, vendría a enriquecer el vasto acervo de las letras nacionales... (Castellanos, 1998: 210-211).

De igual manera, pone de manifiesto la credibilidad que frente a la opinión pública tiene un medio de comunicación como este:

... el anuncio estaba allí, en el periódico, en letra de molde, luego era la verdad, porque para muchos debe ser verdadero y respetable todo lo que está escrito en letras de molde (Castellanos, 1998: 209).

En el primero de los fragmentos citados, las comillas son un recurso al que Rivas Groot acude como indicador lingüístico que señala al lector la presencia de la ironía (cf. Alvarado Ortega, 2006: 7). Asimismo, el enunciado entre comillas actúa como elemento hiperbólico, cuyo carácter exagerado intensifica el sentido mismo de la ironía. El uso de este indicador está igualmente presente en otros momentos del relato: «honor», «obra monumental», «ilustre autor», «maestro», entre otros.

Por otro lado, la ironía en el segundo fragmento es marcada mediante la repetición, acción que enfatiza y potencializa, en este caso, el contenido de verdad y su relación de consecuencia con un aspecto meramente superficial: la relevancia dada a las letras de molde. Es importante mencionar que esta mirada crítica a la práctica del periodismo está relacionada, además, con el estrecho vínculo de los escritores modernistas con este medio, como apunta Castellanos:

Hay presentes juicios sobre el periodismo y la sociedad. Los modernistas estuvieron conectados al periodismo, pues era la actividad que les permitía publicar en un mercado editorial pobre. Casi todos publicaron sus producciones primero en los periódicos. En muchos casos esto creó una situación de dependencia, al tener que estar al servicio de los intereses del periódico (Castellanos, 1998: 172).

$\mathrm{Al}$ escaso mercado editorial que refiere Castellanos se suman el talante prepotente que rodea a esta actividad y el poder de venta que adquiere un nombre de campanillas, actitudes que Rivas Groot pone de manifiesto en el afán por una obra de la que se conoce solo su supuesta naturaleza histórico-arqueológica, materializada, precisamente, en las letras de molde de un clasificado:

Los editores llegaron a su puerta: ellos, los que devuelven con desdén un manuscrito, ofrecían el oro y el moro por la obra... (Castellanos, 1998: 212).

En esta cita, los dos puntos marcan una pausa enfática que conecta con un deíctico anafórico, signo que, a su vez, se convierte en señalador de un comportamiento reprochable, enmarcado por lo ilusorio. Ese espejismo que sedujo por igual a las academias y sus firmes tradiciones. He ahí la ironía:

... pero las academias no renunciaron a la gloria y a la satisfacción de abrirle las puertas y nadie, al fin de una sesión, se resignaba a volver a su casa sin haberse acercado a estrechar su mano, a cruzar dos palabras y a preguntarle cuándo leería su discurso de recepción... (Castellanos, 1998: 212). 
El tono satírico de este relato está determinado por la ironía, y el silencio es el catalizador en el discurrir de su protagonista. El silencio evasivo de sus primeras incursiones lo confirmó como el ilustre autor de una obra ignota y monumental, su silencio sugerente e intencional lo convirtió en maestro, y el silencio definitivo de la muerte lo elevó a la talla de sabio, un sabio incomprendido:

... Pero ¿cómo permitir que se ignorase en la patria de éste que en otros países se poseía y conservaba el trabajo de aquel sabio, quien acaso no había sido comprendido de sus compatriotas? (Castellanos, 1998: 212-213).

La vida de don Narciso Gómez Fernández, ese «hombre práctico, de pocas letras, de buen sentido y mejores rentas» (Castellanos, 1998: 206), es la puesta en escena de una farsa que simboliza una sociedad y sus intereses, la escenificación de una sociedad impregnada de un complejo de bastardía cultural. Después de todo, el mundo es el gran teatro de la vida: vita theatrum.

\section{Conclusiones}

Aun cuando «Rocinante» y «Día de inocentes» tratan, en principio, temáticas vinculadas a la estética como «la importancia del modelo en la creación artística» y al «origen falso de algunas figuras de las letras» (Castellanos, 1998: 186-187), estos relatos reflejan la importancia que, para Rivas Groot, tenía la práctica literaria como medio para exponer las inquietudes propias de su tiempo, y como instrumento de reivindicación social (cf. Maya, 1951: 9). Asimismo, brindan testimonio de una época, cuya problemática hoy, un siglo más tarde, no dista mucho de aquella.

En «Rocinante», la intención crítica de Rivas Groot se revela mediante la conjunción de múltiples voces: Rivas Groot en calidad de habitante del mundo, Rivas Groot en cuanto autor, la ambivalencia entre el yo real y el yo fictivo, en la cual la copresencia textual y el simbolismo de lo aparente adquiere un carácter distinto, el sentido de denuncia. Por otra parte, la crítica en «Día de inocentes» se materializa en el juego de ironías, toma la forma de la sátira, y en ella el autor expresa su desacuerdo con el proceder de algunas esferas de la sociedad y su contribución en la construcción de ídolos de barro, en este caso, de ídolos de papel.

\section{Bibliografía}

$\checkmark$ ALARCOS LlORACH, Emilio, et al. (1989). Lengua española, COU. Madrid: Santillana.

\ Alvarado ortega, M. Belén (2006). «Las marcas de la ironía». Interlingüística 16, pp. 1-11. https://bit. ly/3B1Zx63

У CASTEllanos, George N. (1998). Modernismo y modernidad en José María Rivas Groot. Bogotá: Instituto Caro y Cuervo.

y Cervantes, Miguel de; RICO, Francisco; VARGAS LLOSA, Mario (2004). Don Quijote de la Mancha (edición del IV Centenario). Real Academia Española; Asociación de Academias de la Lengua. Madrid: Santillana Ediciones Generales.

ע GenETTE, Gérard (1989). Palimpsestos. La literatura en segundo grado. Trad. de C. Fernández. Madrid: Taurus.

y GÓMEZ RESTREPO, Antonio (s.f.). José María Rivas Groot. https://bit.ly/2UlQYQv 
ע GUTiÉRreZ burón, Jesús (2008). «Cervantes y "El Quijote” en las exposiciones de Bellas Artes del Siglo XIX». Anales de Historia del Arte, Volumen extraordinario, pp. 455-474. https://bit.ly/3pqk933

У GUTIÉRREZ ORDóÑEZ, Salvador (2020). Comentario pragmático de textos literarios. Madrid: Arco/Libros-La Muralla.

У IGLESIAS AMORÍN, Alfonso (2009). «Los intelectuales españoles y la guerra del Rif. (1909-1927)». In: Los intelectuales españoles, pp. 59-77. https://bit.ly/2UpMSHf

У MAYA, Rafael (1951). «José María Rivas Groot». In: José María Rivas Groot. Novelas y cuentos, pp. 7-20. Bogotá: Editorial ABC. https://bit.ly/2Izv3T7

ע MÉNDEZ GUERrero, Beatriz (2016). «La interpretación del silencio en la interacción. Principios pragmáticos, cognitivos y dinámicos». Pragmalingüística 24, pp. 169-186. https://doi.org/10.25267/Pragmalinguistica.2016.i24.09

У MERCADO CARDONA, Homero (1999). José María Rivas Groot: algunas aproximaciones filológico-estilísticas. Bogotá: Instituto Caro y Cuervo.

ע MINISTERIO DE EDUCACIÓN NACIONAL (1936). Cuentos por José María y Evaristo Rivas Groot. Bogotá: Editorial Minerva. https://bit.ly/370S4aq

ע ORTIZ MESA, Luis Javier. (2010). «La Regeneración en Colombia (1878-1902)». In: Diana Bonnet; Michael LaRosa; Mauricio Nieto (compiladores). Colombia. Preguntas y respuestas sobre su pasado y su presente. Bogotá: Ediciones Uniandes, pp. 231-254.

У REYES, Graciela (1984). Polifonía textual: la citación en el relato literario. Madrid: Gredos.

๖ SANTA, Eduardo (1990). «Consideraciones en torno a la novela "Pax"». Thesaurus, Tomo XLV, 2, pp. 441465. https://bit.ly/2URPfCI

\author{
Pedro Javier Casas Malagón \\ Universidad de La Sabana \\ Carrera 108A \# 77D-92 \\ 111041 \\ Colombia
}

